\title{
MOBILE LEARNING ADOPTION AT THE SCIENCE MUSEUM GROUP
}

\author{
Ruel Welch, Temitope Alade and Lynn Nichol \\ University of Worcester \\ Worcester, United Kingdom
}

\begin{abstract}
Mobile learning (mLearning) at the Science Museum Group (SMG) in the United Kingdom (UK) could reduce ICT support calls, increase productivity and develop technical knowledge SMG staff. However, challenges are pervasive in any technological adoption. This paper uses the unified theory of acceptance and use of technology (UTAUT) model to explain the determinants of mLearning adoption at the Science Museum Group (SMG).

Results indicate that the UTAUT constructs, performance expectancy, effort expectancy, social influence and facilitating conditions are all significant determinants of behavioral intention to use mLearning. A newly proposed construct, self-directed learning was not a significant determinant of behaviour intentions. Further examination found age and gender moderate the relationship between the UTAUT constructs. These findings present several useful implications for mLearning research and practice for ICT service desk at SMG. The research contributes to mLearning technology adoption and strategy.
\end{abstract}

\section{KEYWORDS}

Mobile Learning, Workplace Learning, Technological Adoption

\section{INTRODUCTION}

The Science Museum Group (SMG) service desk team in the United Kingdom (UK) faces Service Level Agreement (SLA) breaches due to an overstretched Service Desk team. Furthermore, this team suffers a recruitment freeze due to significant reductions in funding made by the Department for Culture, Media and Sport (DCMS) in the UK. Thus, service desk staff are required to manage incidents and other demands with minimal resources.

The aim of this paper is to derive models for adoption of mobile learning (mLearning) as a form of just-in-time knowledge acquisition. This will be achieved by addressing two objectives

1. Analyze questionnaire data establishing factors contributing to mLearning adoption at SMG

2. Provide recommendations to the SMG's service desk management on improving the implementation and adoption of mLearning in the SMG in order to achieve operational objectives.

\section{1 mLearning in the Workplace}

While mLearning research has grown in popularity in the milieu of educational institutes i.e. schools, colleges and universities, its use as a knowledge acquisition method remains a relatively new concept in the field of organizational learning, more specifically, communities of practice (Lave and Wenger, 1991). It is widely accepted that staff training and staff propensity to be trained is a contributing factor in facilitating new technological adoption. Rossett and Marshall's (2010) research found the use of mobile devices for learning was uncommon practice. As a result, this presents a missed opportunity as mLearning provides useful just-in-time knowledge acquisition. The focus of most researchers over the last few years has been on evaluating the effects of mLearning (Chee et al., 2016). 


\subsection{Main Contributions}

The extent to which mLearning can be used as a tool for knowledge acquisition and its impacts on productivity and specifically, the effective management of ICT support calls in the museum sector remain largely unknown. Due to lack of research in this area, this study on mLearning adoption in SMG is important to senior SMG ICT management as it will provide insight and help to illuminate important drivers for technological adoption. These contributions are useful within and outside the museum sector as it provides insights for technological adoption strategies.

\section{RESEARCH MODEL AND HYPOTHESES}

Venkatesh et al. (2003) research found that the constructs appear to be significant determinants of user acceptance and usage behaviour. The remainder of this section presents a definition of each of the determinants and their relationship across eight technology acceptance models. Additionally, stating the role of the key moderators (gender and age), and proposing the theoretical rational for the hypotheses that will be advanced in this study. Finally, this section will present the adaptation of the UTAUT model that will be used in this research.

Performance expectancy: Venkatesh et al. (2003) defines performance expectancy as the extent an individual considers the utility of an information system and the performance gains attained in their job from using it. There are five constructs pertaining to performance expectancy, namely perceived usefulness (TAM/TAM2 and C-TAM-TPB), extrinsic motivation (MM), job-fit (MPCU), relative advantage (IDT), and outcome expectations (SCT).

Modification to the performance expectancy construct to incorporate the mLearning context suggests SMG staff will find it useful to apply mLearning as a knowledge acquisition solution.

Numerous authors ((Morris and Venkatesh 2000; Venkatesh and Morris 2000) theorised that gender and age have been shown to play moderating roles in the context of technological adoption. Research conducted by Minton and Schneider (1980) on gender differences suggests that adult males tend to be more task-oriented than adult females. Whilst, research on job-related attitudes (Hall and Mansfield 1975; Porter 1963) suggests that younger workers place more emphasis on extrinsic rewards. Therefore, the influence of performance expectancy on behavioural intention will be moderated by gender and age, such that the effect of gender will be stronger for men, in particular, younger men Venkatesh et al. (2003). Therefore, this study will advance the following hypotheses:

Hypothesis 1: Performance expectancy has a positive effect on behavioural intentions to use mLearning

Hypothesis 2: Performance expectancy influences behavioural intention to use mLearning more strongly for male staff than for female staff

Hypothesis 3: Performance expectancy influences behavioural intention to use mLearning more strongly for younger staff than for older staff

Effort expectancy: Venkatesh et al. (2003) defines effort expectancy as the extent to which the use of the information system is achieved with ease. Three constructs from three models denote the concept of effort expectancy: perceived ease of use (TAM/TAM2), complexity (MPCU), and ease of use (IDT).

The notion of effort expectancy being a stronger determinant of an individuals' intention for women than men is supported by prior research (Venkatesh and Morris 2000; Venkatesh et al. 2000). Additionally, based on similar claims in the context of performance expectancy, it is anticipated that gender and age will have comparable moderating effects on effort expectancy. Accordingly, based on the same arguments presented in UTAUT, it is anticipated that individual acceptance of mLearning will depend on the extent to which the use of it will be achieved with ease. Additionally, Rossett and Marshall's (2010)'s research found the use of mobile devices for learning was uncommon in current practice and was hardly considered for staff training albeit formal, non-formal or informal work-based learning. Moreover, it is anticipated that gender and age will have comparable moderating effects on effort expectancy. Thus, the following hypotheses will be tested:

Hypothesis 4: Effort expectancy has a positive effect on behavioural intention to use mLearning

Hypothesis 5: Effort expectancy influences behavioural intention to use mLearning more strongly for female staff than for male staff 
Hypothesis 6: Effort expectancy influences behaviour intention to use mLearning more strongly for older staff than for younger staff

Social influence: Venkatesh et al. (2003) defines social influence as the extent to which an individual perceives that either senior staff members or someone that can influence behaviour thinks they should use the information system. The construct social influence is represented as subjective norm in TRA, TAM2, TPB/DTPB and C-TAM-TPB, social factors in MPCU, and image in IDT.

Some authors (Venkatesh et al. (2003); Wu et al., 2008; Indrawati et al., 2010) suggest that social influence affects the intention to use new technology. It has been theorised that women tend to be more sensitive to the opinions of others and therefore find social influence to be more prominent when forming an intention to use new technology (Miller 1976; Venkatesh et al. 2000). Additionally, Rhodes' (1983) research suggests that older staff members are more likely to place emphasis on social influences. Transposing these arguments to the context of mLearning is the rationale for anticipating that social influence is a significant determinant of behaviour intentions to use mLearning, likewise, will be moderated by gender and age in the same way. Thus, the following hypotheses will be advanced.

Hypothesis 7: Social influence has a positive effect on behavioural intention to use mLearning

Hypothesis 8: Social influence influences behavioural intention to use mLearning more strongly for female staff than for male staff

Hypothesis 9: Social influence influences behavioural intention to use mLearning more strongly for older staff than for younger staff

Self-directed learning: Livingstone (2006) defines self-directed or informal learning as any activity involving the pursuit of understanding, knowledge, or skill that occurs without the presence of externally imposed curricular criteria' (p206) or instructor (Chee et al., 2016), research on mobile learning trends between 2010 and 2015 found, that informal learning was the most popular approach within mLearning research, compared to other learning approaches such as formal learning and non-formal.

From both a techno-centric and andragogical viewpoint, aspects of mLearning can be considered as a kind of self-directed eLearning via mobile devices. For example, both eLearning and mLearning are learner centred thus, self- learning (Behera, 2013). It is expected that a person's level of self-directedness of learning will have a positive influence on his or her behavioural intention to use mLearning as a knowledge acquisition intervention. Beck's (1983) research on cognitive therapy suggests evidence to support the notion that men are more likely to possess autonomous personality traits than women. As a result, it is anticipated that the effect of self-directed learning on mLearning acceptance will be moderated by gender and age, such that the effect will be stronger for men, particularly older men. Thus, the following hypotheses will be tested:

Hypothesis 10: Self-directed learning has a positive effect on behavioural intentions

Hypothesis 11: Self-directed learning influences behavioural intentions to use mLearning more strongly for Male staff than for Female staff

Hypothesis 12: Self-directed learning influences behavioural intention to use mLearning more strongly for older staff members than for younger staff members

Facilitating conditions: Venkatesh et al. (2003) defines facilitating conditions as the extent to which an individual perceives the organisational and technical infrastructure's ability to provide support for the information system. The construct facilitating conditions is typified by three different constructs from five models; perceived behavioural control (TPB/DTPB, C-TAM-TPB), facilitating conditions (MPCU), and compatibility (IDT).

Based on arguments presented by Venkatesh et al. (2003) it is anticipated that the effect of facilitating conditions on mLearning adoption will not be moderated by gender and age. Therefore, this study will advance the following hypothesis:

Hypothesis 13: Facilitating conditions does not impact behavioural intentions

Behaviour intentions to use mLearning: Based on arguments presented by Venkatesh et al. (2003) regarding behavioural intentions. This research expects that behavioural intention would have a significant positive effect on use behaviour. Thus, the following hypothesis will be tested:

Hypothesis 14: Behaviour intentions has a positive effect on Use behavior Learning, Workplace Learning, Technological Adoption. 


\section{METHODOLOGY}

\subsection{Data Collection}

A structured questionnaire was created using an electronic form (google form) and disseminated to both SMG staff via emails to gatekeepers. Thus, convenience sampling, a non-random sampling technique was used. The questionnaire consisted of SMG specific questions, demographic questions, internet connected mobile device usage questions and reviewed UTAUT questions. Each item on the UTAUT survey is scored on a 5-point Likert scale. The wording of the items on the survey were reviewed by a selection of SMG staff for the purpose of clarity and completeness.

Data Screening: The data was screened for missing data, unengaged responses, outliers and data normality. There were no missing data in the dataset. Five cases were removed due to unengaged responses. Mahalanobis distance was calculated to locate and remove outliers. No cases were removed as the maximum value calculated for this dataset was 67.089 and the critical value is 69.3.

Data normality is examined by conducting a Skewness and Kurtosis test. The results of the analysis showed fairly normal distributions for the indicators of latent factors and all other variables were observed. However, mild Kurtosis was found in seven items. The Kurtosis observed ranged from benign to 3.17. This does fall below more lenient rules suggested by Sposito et al. (1983) who recommend 3.3 as the upper limit.

\subsection{Data Analysis}

Data was analysed using the Structural Equation Modelling (SEM) approach. SEM is a comprehensive statistical modelling technique used to specify confirmatory factor analysis models, regression models and complex path models. Thus, this approach was used in this study. Anderson and Gerbing (1988) recommend a two-step approach which this study adopted. First, an examination of the measurement model for reliability and validity was conducted. Secondly, the assessment of the structural model to test the suitability of the model and research hypotheses was carried out.

\section{RESULTS AND DISCUSSIONS}

\subsection{Participants}

This section describes the descriptive statistics for the 118 staff whose responses from the mLearning adoption survey was usable.

Sixty-eight $(58 \%)$ of the staff were female, and fifty $(42 \%)$ were male. Participants' age group were reported as follows: $3(2 \%)<21 ; 41(35 \%) 21$ - 30; 36 (30\%) 31 - 40; 23 (20\%) 41 - 50; 15 (13\%) >50;

The highest educational attainment of staff members was reported as $3(3 \%)$ having attained a Secondary school education; 5 (4\%) Further Education (FE) College; 11 (9\%) Higher Education (HE) college 53 (43\%) Bachelor; 46 (39\%) Postgraduate.

All of the main departments of SMG were represented; 8 (7\%) Collections Services; 6 (5\%) Commercial Experience; 1 (1\%) Curatorial / Library / Archives; 6 (5\%) Development; 5 (4\%) Directorate; 10 (9\%) Exhibitions; 14 (12\%) Finance / Procurement; 21 (18\%) ICT; 9 (8\%) Learning; 5 (4\%) Marketing and Comms; 5 (4\%) Masterplan, Estates \& Design; 12 (10\%) Operations (including Visitor Fundraising); 4 (3\%) People \& Culture; 6 (5\%) Retail; 6 (5\%) Other.

$43(36 \%)$ staff had management responsibilities, leaving $75(64 \%)$ that did not.

A large majority $(114 ; 97 \%)$ of the participants reported they had used a mobile device at home with Internet access. Seventy-seven (65\%) said they had used a mobile device at work, seventy (59\%) of staff members reported that they used their mobile device to acquire knowledge or skill, and twenty-two (19\%) stated that they used their mobile device to access SMG knowledge articles or ICT Training YouTube channel. 


\subsection{Evaluation of the Measurement Model}

Exploratory Factor Analysis (EFA) and Confirmatory Factor Analysis (CFA) are used to explain relationships among several observed variables using a smaller number of unobserved variables also known as latent variables or factors (Hair et al, 2006). The overall assessment was carried out using EFA, CFA, SPSS 20 and AMOS 25 tools to examine convergent and discriminant validity. Convergent validity is dependent on three indicators: 1) the reliability of each construct, 2) the item reliability of each measure (factor loading), 3) the average variance extracted (AVE). Constructs are considered to have convergent validity when the composite reliability (CR) exceeds the criterion of 0.70 and the average variance extracted is above 0.50 (Hair et al. 2006). Table 1 shows the factor loadings, the AVE, CR and the Cronbach Alpha values. All AVE's were above the 0.5 threshold and all CRs were above 0.7. Sixteen items were removed due to low loadings, cross loadings and optimising the reliability analysis. Thus, the results support the convergent validity of the scales. Additionally, all Alpha values are above the 0.7 threshold thus exhibiting good reliability (Nunnally and Bernstein, 1994).

Table 1. Results for the measurement model

\begin{tabular}{lll}
\hline Heading level & Example & Font size and style \\
\hline Performance Expectancy & 1. INTRODUCTION & 13 point, bold \\
Effort Expectancy & 1.1 Printing Area & 13 point, bold \\
Social Factors & $\mathbf{1 . 1 . 1}$ Text & 11 point, bold \\
Facilitating Conditions & & \\
Self-Directed & & \\
Behavioural Intention & & \\
Use & & \\
\hline
\end{tabular}

The assessment of discriminant validity is the square root of the AVE for each construct compared with the inter-factor correlations between that construct and all the other constructs. If the AVE is higher than the squared inter-scale correlations of the construct, it shows good discriminant validity (Gefen et al. (2000); Hair et al. 2006). However, regarding this measurement model, the square root of the AVE for EE is less than its correlation with BIU and the square root of the AVE for PE is also less than its correlation with BIU. Therefore, according to Gefen et al. (2000) this measurement model is exhibiting poor discriminant validity. This means that some constructs are correlated with others that are designed to measure theoretically different concepts. See Table 2 for results.

Table 2. Results for the measurement model

\begin{tabular}{|c|c|c|c|c|c|c|c|}
\hline & $\mathrm{EE}$ & SF & Use & $\mathrm{FC}$ & SD & $\mathrm{PE}$ & $\mathrm{BI}$ \\
\hline $\mathrm{EE}$ & 0.830 & & & & & & \\
\hline SF & $0.614 * * *$ & 0.900 & & & & & \\
\hline Use & $0.779 * * *$ & $0.615 * * *$ & 0.926 & & & & \\
\hline $\mathrm{FC}$ & $0.291 * *$ & $0.549 * * *$ & $0.300 * *$ & 0.837 & & & \\
\hline $\mathrm{SD}$ & $0.580 * * *$ & $0.367 * *$ & $0.477 * * *$ & $0.292 * *$ & 0.793 & & \\
\hline $\mathrm{PE}$ & $0.658 * * *$ & $0.783 * * *$ & $0.688 * * *$ & $0.510 * * *$ & $0.482 * * *$ & 0.793 & \\
\hline BIU & $0.840 * * *$ & $0.792 * * *$ & $0.824 * * *$ & $0.465^{* * *}$ & $0.495 * * *$ & $0.842 * * *$ & 0.906 \\
\hline
\end{tabular}

Common Method Variance: The purpose of testing for common method variance (CMV) is to estimate to what degree biases exist. Common marker variable statistical technique was used in this study to estimate such variance. Lindell and Whitney (2001) recommend using variables with low correlations between observed variables as measures for the latent method variable. The results show that the constrained and unconstrained models are invariant. Therefore, failing to detect the presence of any specific response bias affecting the model.

\subsection{Measurement Model Fit}

Seven common model-fit measures were used to assess the model's overall goodness-of-fit. Chi-square mean/Degree of freedom $(\chi 2 / d f)$, Incremental fit Index (IFI), Tucker Lewis Index (TFI), Comparative fit index (CFI), Root mean square error of approximation (RMSEA), Standard root mean square residual 
(SRMR). Overall, the results of the proposed research model showed an adequate fit: ( $\chi 2 / \mathrm{df} 1.646$., GFI 0.804, IFI .948, TLI .934, CFI .947, RMSEA .075, SRMR = .053).

Multivariate and outliers: A cook's distance analysis was carried out to determine if any multivariate influential outliers existed. There were no observed cases of a Cook's distance greater than 1. Most cases were less than 0.280 , indicating no presence of influential outliers.

Multicollinearity: An examination of the Tolerance and Variance Inflation Factors (VIF) was carried out to assess multicollinearity. The multicollinearity does not exist in a regression model when the Tolerance value is greater than 0.1 and the VIF value is less than 10 (Field, 2009). The results of the Tolerance and VIF indicated that all Tolerance values were greater than 0.1 , and the VIF values for all UTAUT constructs were less than 5. Thus, the assumption of the absence of multicollinearity was met.

\subsection{Evaluation of Structural Model}

The second step is to assess the structural model which includes testing the theoretical hypothesis and the relationships between the latent constructs. Seven common model-fit measures were used to assess the model's overall goodness-of-fit. Overall, the results of the proposed research model showed an adequate fit: $(\chi 2$ /df 1.691., GFI .817, IFI .945, TLI .932, CFI .944. RMSEA .078, SRMR .0582). These results provided evidence that the model fit the data adequately. Thus, able to proceed to investigate the determinants, age and gender differences in mLearning adoption. Table 3 lists the path coefficients and their significance.

As expected, hypotheses $(\mathrm{H} 1, \mathrm{H} 4, \mathrm{H} 7)$ representing the relationship among the main constructs $(\mathrm{PE}, \mathrm{EE}$, SI) to BIU were supported in this study. The hypothesis that was not supported was H10: SD to BIU. Self-Directed did not significantly predict behaviour intention to use mLearning $(-0.03, n . s)$. Surprisingly, the data proved that FC did significantly predict behaviour intention to use mLearning. Thus, H13 was not supported.

Table 3. Structural model results

\begin{tabular}{|c|c|c|c|}
\hline Path/Hypothesis & Beta & t-value & Results \\
\hline $\mathrm{PE} \rightarrow \mathrm{BIU}(\mathrm{H} 1)$ & $0.347 * *$ & 3.244 & Supported \\
\hline $\mathrm{EE} \rightarrow \mathrm{BIU}(\mathrm{H} 4)$ & $0.460 * * *$ & 5.590 & Supported \\
\hline $\mathrm{SI} \rightarrow \mathrm{BIU}(\mathrm{H} 7)$ & $0.199 *$ & 2.160 & Supported \\
\hline $\mathrm{SD} \rightarrow \mathrm{BIU}(\mathrm{H} 10)$ & -.032 & -0.504 & Ns \\
\hline $\mathrm{FC} \rightarrow \mathrm{BIU}(\mathrm{H} 13)$ & $0.109 \dagger$ & 1.822 & Not Supported \\
\hline $\mathrm{FC} \rightarrow \mathrm{USE}$ & -0.206 & -2.690 & Negative relationship \\
\hline $\mathrm{BIU} \rightarrow \mathrm{USE}(\mathrm{H} 14)$ & 0.960 & 10.659 & Supported \\
\hline \multicolumn{4}{|c|}{$\begin{array}{c}\text { Model fit indices: } \chi^{2} / d f \text { 1.691., GFI 0.817, IFI .945, TLI .932, CFI } .944 \\
\text { RMSEA .078, SRMR = .0582 }\end{array}$} \\
\hline
\end{tabular}

The results of the analyses of gender and age differences are outlined in Tables 4 and 5 respectively, listing the path coefficients and their significance. Additionally, a multigroup comparison test was carried out via a chi-square difference test to test significance of moderation. This resulted in the p-value of the chi-square difference test to be significant.

Table 4. Structural model results (moderators male and female)

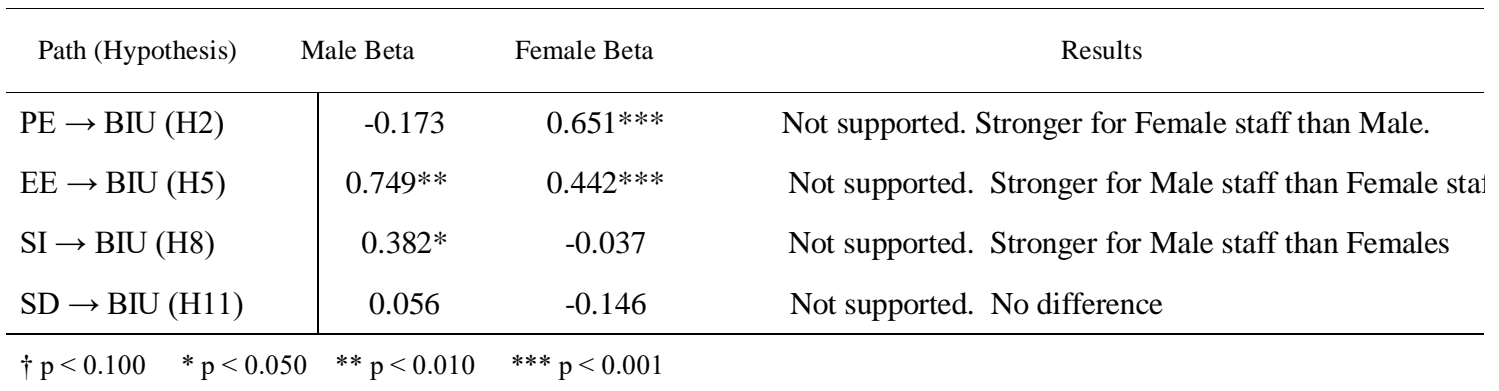


Participants were divided into two groups: the older group consisted of ages greater than 30 years and the younger group with ages less than or equal to 30 years. A Multigroup comparison test was carried out via a chi-square difference test to test significance of moderation. It was observed that the p-value of the chi square difference test is statistically significant. Therefore, the model differs across the different groups (Younger staff and Older Staff).

Table 5. Structural model results (moderators younger staff and older staff)

\begin{tabular}{l|ccl}
\hline \multicolumn{1}{c}{ Path } & Older Beta & Younger Beta & \multicolumn{1}{c}{ Results/Interpretation } \\
\hline $\mathrm{PE} \rightarrow$ BIU (H3) & $0.426^{* * *}$ & 0.240 & Supported. stronger for younger staff than older staff \\
$\mathrm{EE} \rightarrow$ BIU (H6) & $0.501^{* * *}$ & 0.248 & Supported. Only significant for older staff \\
$\mathrm{SI} \rightarrow \mathrm{BIU}(\mathrm{H} 9)$ & 0.097 & $0.895^{* * *}$ & Not supported. Stronger for Younger staff than older staff \\
$\mathrm{SD} \rightarrow \mathrm{BIU}(\mathrm{H} 12)$ & -0.082 & $0.256^{*}$ & Not supported. Stronger for Younger staff than older staff \\
\hline \multicolumn{2}{c}{$\uparrow<0.100 \quad * \mathrm{p}<0.050 * * \mathrm{p}<0.010$} & $* * * \mathrm{p}<0.001$ &
\end{tabular}

Finally, $\mathrm{R}^{2}$ value of the behavioural intention was 0.875 and that of the usage was 0.683 . Translating these values into explanatory power, behavioural intention was $87.5 \%$ whilst use was $68.3 \%$. This means that the explanatory power of this model is higher than Venkatesh et al. (2003) research reporting $70 \%$ explanatory power.

\section{CONCLUSION}

The purpose of this study was to use the UTAUT model as a theoretical framework to understand key factors that influences mLearning adoption at SMG. Due to the dearth of published research on the use of UTAUT in Museums, it can be assumed, this is the first assessment of the UTAUT model in relation to mLearning in the milieu of the Museum sector. The analysis of both the data captured and the UTAUT model was carried out using SEM. The findings from this study showed that there are age and gender differences that moderate the relationship between the UTAUT constructs. It was also found that the newly added self-directedness construct was not a predictor of behavior intentions to use mLearning at SMG. The conclusions in this research will help the diffusion of mLearning at SMG and across the museums, galleries, arts, academic, charitable and cultural heritage sector.

Numerous authors believe the future direction of research is motivated and dictated by mobile device applications. (Pereira and Rodrigues 2013; Lim and Churchill 2016). Lim and Churchill (2016) suggests that research should also focus on aspects of multimedia content, communication, digital storytelling, social networking and cloud computing.

Senior management at SMG are keen to explore machine learning capabilities as a way of automating many of the service desk processes.

The results and conclusion are limited and not intended to be exhaustive. Limitations exists in the interpretation of the findings thus suggestions throughout this study and specifically in the discussions section will require further research to confirm their validity.

This study used a single-time approach which was different from the research proposed by Venkatesh et al. (2008) where three measuring times of the same groups of samples were applied.

An inherent, limitation of the questionnaire is its static nature. Recipients can only answer the questions that researchers thought to ask. Therefore, it is acknowledged that further information may have been omitted.

\section{REFERENCES}

Anderson, J. C. and Gerbing D. W. (1988) Structural Equation Modeling in Practice: A Review and Recommended Two-Step Approach, Psychological Bulletin (103) 3, pp. 411-423.

Baumgartner, H. and Homburg, C. (1995) Applications of structural equation modelling in marketing research: A review. International journal of research in Marketing. 13, pp 139-161 
Beck, A. T. (1983) Cognitive therapy of depression: new perspectives. In P. J. Clayton \& J. E. Barrett (Eds), Treatment of depression: old controversies and new approaches (pp. 265-290). New York: Raven Press.

Behera, S. K (2013) E- and M-Learning: A comparative Study. International Journal on New Trends in Education and Their Implications. Vol 4. (3) pp. $65-78$

Chee, K. N., Yahaya, N., Ibrahim, N.H. and Hasan, M.N. (2016) Review of Mobile Learning Trends 2010-2015: A Meta-Analysis. Educational Technology \& Society, 20 (2), 113-126.

Field, A.P. (2009), Discovering Statistics Using SPSS, Sage, London

Gefen, D., Straub, D. and Boudreau, M, (2000) Structural Equation Modeling and Regression: Guidelines For Research Practice. Communications of the Association for Information Systems. Vol 4. (7)

Hair, J. F., Black, B., Babin, B. J., Anderson, R. E., and Tatham, R. L. (2006) Multivariate Data Analysis (6 $6^{\text {th }}$ Ed.) New Jersey: Pearson Prentice Hall

Hall, D., and Mansfield, R. (1995) Relationships of Age and Seniority with Career Variables of Engineers and Scientists, Journal of Applied Psychology Vol 60. (2). pp. 201-210

Hu, L-T and Bentler, P. M. (1999) Cutoff criteria for fit indexes in covariance structure analysis: Conventional criteria versus new alternatives. Structural Equation Modelling, Vol 6. (1) pp- $1-55$

Indrawati, R. M. and Chew, K.- W. (2010) "A Conceptual Model for Behavioral Intention to Use 3G Mobile Multimedia Services in Indonesia," Proceedings of the International Symposium on Information Technology, Kuala Lumpur.

Lave, J., and Wenger, E. (1991) Situated Learning: Legitimate Peripheral Participation. Cambridge: Cambridge University Press

Lim, C. P. and Churchill, D. (2016) Editorial: Mobile learning. Interactive Learning Environments, 24(2), 273-276. http://www.tandfonline.com/eprint/JzIGpwEKsJASCuqna6ZE/full. Interactive Learning Environments. 24. 273-276.

Lindell, M. K. and Whitney, D. J. (2001) Accounting for Common Method Variance in Cross-Sectional Research Designs. Journal of Applied Psychology. Vol.86 (4), $114-121$

Livingstone, D. (2006) Informal Learning: Conceptual Distinctions and Preliminary Findings. Counterpoints, 249, 203-227. Retrieved from http://www.jstor.org/stable/42979596

Miller, J. B. (1976) Toward a New Psychology of Women, Beacon Press, Boston,

Minton, H. L., and Schneider, F. W. (1980) Differential Psychology, Waveland Press, Prospect Heights, IL,

Morris, M. G., and Venkatesh, V. (2003) Age Differences in Technology Adoption Decisions: Implications for a Changing Workforce, Personnel Psychology. Vol 53. 2. pp. 375-403

Nunnally, J. C., and Bernstein, I.H. (1994) Psychometric theory (3rd Ed.). New York: McGraw-Hill. Inc.

Pereira, O. R. E. and Rodrigues, J. J. P. C. (2013) Survey and Analysis of Current Mobile Learning Applications and Technologies, ACM Computing Surveys, Vol. 46, No. 2

Porter, L. J (1963) Job Attitudes in Management: Perceived Importance of Needs as a Function of Job Level, Journal of Applied Psychology. Vol 47. 2, pp. 141-148

Rhodes, S. R. (1983) Age-Related Differences in Work Attitudes and Behavior: A Review and Conceptual Analysis, Psychological Bulletin. Vol 93. (2) pp. 328-36

Rossett, A., and Marsahll, J. (2010) E-learning: What's old is new again. Training and Development, Vol.64 134 - 38.

Sposito, V. A., Hand, M. L., and Skarpness, B. (1983) On the efficiency of using the sample kurtosis in selecting optimal lpestimators. Communications in Statistics-simulation and Computation, 12(3), 265-272

Venkatesh, V., and Morris, M. G. (2000) Why Don’t Men Ever Stop to Ask for Directions? Gender, Social Influence, and Their Role in Technology Acceptance and Usage Behavior, MIS Quarterly, Vol 24. (1), pp. 115-139

Venkatesh, V., Morris, M. G., and Ackerman, P. L. (2000) A Longitudinal Field Investigation of Gender Differences in Individual Technology Adoption Decision Making Processes, Organizational Behavior and Human Decision Processes. pp. 33-60

Venkatesh, V., Morris, M. G., Davis, G. B. and Davis, F. D. (2003) User acceptance of information technology: toward a unified view. MIS Quarterly, Vol 27, (3), pp 425-478

Wu, Y.- L., Tao, Y.- H. and Yang, P.- C. (2008) The Use of Unified Theory of Acceptance and Use of Technology to Confer the Behavioral Model of 3G Mobile Telecommunication Users, Journal of Statistics \& Management Systems, Vol 11 (5), pp 919-94 